\title{
Transformações do boto na Amazônia: relações transversais entre campos de conhecimento
}

Transformations of the boto in the Amazon:

transversal relations between fields of knowledge

Kauã Vasconcelos e Felipe Süssekind

\section{(2) OpenEdition Journals}

\section{Edição electrónica}

URL: http://journals.openedition.org/aa/6618

DOI: 10.4000/aa.6618

ISSN: 2357-738X

\section{Editora}

Programa de Pós-Graduação em Antropologia Social (UnB)

\section{Edição impressa}

Paginação: 24-43

ISSN: 0102-4302

\section{Refêrencia eletrónica}

Kauã Vasconcelos e Felipe Süssekind, «Transformações do boto na Amazônia: relações transversais entre campos de conhecimento", Anuário Antropológico [Online], v.45 n.3 | 2020, posto online no dia 16 setembro 2020, consultado o 27 abril 2021. URL: http:// journals.openedition.org/aa/6618; DOl: https://doi.org/10.4000/aa.6618

\section{(c) (i) (9)}

Anuário Antropológico is licensed under a Creative Commons Atribuição-Uso Não-Comercial-Proibição de realização de Obras Derivadas 4.0 International. 


\title{
Transformações do boto na Amazônia: relações transversais entre campos de conhecimento
}

\author{
Transformations of the boto in the Amazon: \\ transversal relations between fields of knowledge \\ DOI: https://doi.org/10.4000/aa.6618
}

\begin{abstract}
Kauã Vasconcelos • Antropólogo independente - Brasil
Mestre em Antropologia Social pelo Museu Nacional, Universidade Federal do Rio de Janeiro.

Felipe Süssekind • Pontifícia Universidade Católica do Rio de Janeiro - Brasil

-Rio). Doutor em Antropologia Social pelo Museu Nacional (UFRJ).

Este artigo elabora uma cartografia de algumas das formas nas quais os botos se manifestam na Amazônia brasileira, em processos entendidos como transformações. O ponto de partida é um experimento de pesquisa de campo colaborativa na Ilha do Marajó, a maior ilha fluviomarinha do mundo, localizada no delta do rio Amazonas. A primeira transformação a ser abordada está ligada à conservação de espécies ameaçadas, e diz respeito à relação, de um lado, entre botos, pescadores e peixes, e, de outro, entre a pesca e outras atividades humanas. A segunda está ligada às narrativas nas quais o boto surge como um homem vestido de branco que seduz mulheres jovens. Por fim, o artigo se volta para a Encantaria, experiência que reúne aspectos das religiões de matriz africana e dos xamanismos indígenas, onde o boto se manifesta como uma entidade sobrenatural. A proposta é que essas diferentes formas sejam entendidas como elementos em um conjunto de transformações, as quais não são redutíveis entre si.
This article proposes a cartography of some of the ways in which river dolphins are represented in the Brazilian Amazon, within processes understood as transformations. The starting point is a collaborative field research experiment conducted in Marajó Island, the world's largest fluvial-marine island, located in the Amazon river Delta. The first transformation to be addressed is linked to the conservation of endangered species, and concerns, on the one hand, the relationship between dolphins, fishermen and fish, and, on the other, between fishing and other human activities. The second concerns the tales in which this animal appears as a man dressed in white seducing young women. Finally, the article turns to the Amazonian Enchantment, an experience that brings together aspects of the African matrix religions and indigenous shamanism, where the river dolphin manifests itself as a supernatural entity. The proposal is to treat those different forms as elements in a set of transformations that are not reducible to each other.

River dolphin. Amazon. Enchantment. Conservation. Transformation. 


\section{Introdução}

O boto é um ser que se transforma. Seu caráter ambivalente foi intuído de diferentes formas e está presente nas experiências de diversos povos ao redor do mundo, desenhando figuras múltiplas ${ }^{1}$. Em toda a região amazônica, essa multiplicidade se desdobra nas interações entre botos e pescadores, nas histórias em que o boto anda pelas festas na forma de um homem atraente que seduz as jovens, ou nos terreiros de religiões de matriz africana, nos quais é uma entidade ligada à linha do fundo da Encantaria (aqui empregamos os termos "religiões de matriz africana" e "encantaria" no sentido dado pelos estudos de religião; "linha do fundo" é um termo nativo mobilizado para se referir à linha de trabalho com os encantados na Amazônia marajoara). O que propomos neste artigo é a elaboração de uma cartografia provisória de algumas dessas formas nas quais o boto se manifesta, entendendo-as como transformações que resultam de processos de diferenciação e aproximação.

O primeiro processo está ligado aos campos da ecologia científica e da conservação. Pensamos, neste caso, no animal que faz dos rios da Amazônia seu habitat, compete com os pescadores e se adapta a um ambiente cada vez mais transformado pelas atividades humanas. Tomaremos como ponto de partida entrevistas realizadas no âmbito de um projeto de pesquisa realizado na costa leste da Ilha de Marajó, a maior ilha fluviomarinha do mundo, localizada no delta do rio Amazonas. A região é habitada por duas espécies de botos. Ambas interagem com diferentes modalidades de pesca, e a interação entre elas e os pescadores é complexa e por vezes descrita como conflituosa no âmbito da ecologia da conservação. A competição pelos mesmos peixes, além disso, estabelece conexões transversais com a observação de uma série de tabus, distanciamentos e precauções em relação aos botos por parte das populações locais.

$\mathrm{O}$ segundo processo que vamos investigar diz respeito às narrativas regionais em torno do boto que surge na forma humana e seduz mulheres jovens. Buscaremos analisar o tema primeiro em seu aspecto mais sociológico, ligado a uma dimensão violenta do colonialismo que se atualiza na vida social amazônica. Por fim, nos voltaremos para uma variante mais propriamente cosmológica, relacionada ao modo como o boto se manifesta enquanto ser encantado nos estudos das religiões de matriz africana e no xamanismo indígena. A Encantaria amazônica nos oferece, neste contexto, diferentes contrastes; entre este mundo e o outro, ou entre o aspecto maléfico e perigoso dos botos, de um lado, e, de outro, as alianças traçadas com eles em suas manifestações como guias espirituais.

Acreditamos que essas que estamos caracterizando como diferentes "transformações" podem ser investigadas sem que sejamos obrigados a reduzir o tema dos botos a apenas uma delas, tomando-a como uma dimensão real, objetiva. Entendemos que uma redução deste tipo obliteraria as outras perspectivas. No plano da ecologia científica, isso acontece, por exemplo, quando os conhecimentos tradicionais são tratados como lendas, crenças ou superstições; no plano das ciências sociais, por outro lado, acontece quando os fenômenos são reduzidos à dimensão exclusivamente humana da ecologia política, na qual a questão ambiental se res-
1 Vide, por exemplo, o estatuto ontológico destes animais entre populações como os Kwakiutl da costa norte-americana (Goldman 1975) e os Yup'ik do Alasca (Fiennup-Riordan 1996). Para contextos euroamericanos (ou Modernos), ver o trabalho de Peace sobre ecoturismo voltado para a observação de baleias (2005) e de Servais a respeito da forma como os ocidentais tendem a representar os golfinhos (2005). Há também, certamente, um conjunto heterogêneo de "Amazônias" a serem apresentadas em suas singularidades, e o boto se manifesta localmente de diversas formas. Não temos a pretensão de abarcar essa multiplicidade. Entretanto, partindo do caso específico da Ilha do Marajó, apostamos em certas conexões e agenciamentos entre diferentes contextos amazônicos, no sentido de delinear o tema do boto também a partir do recurso comparativo. 
tringe ao manejo de recursos naturais. Não pretendemos tampouco tratar cada uma dessas transformações como uma dimensão particular de um fenômeno mais geral para o qual teríamos que fornecer uma explicação. Acreditamos que as variações, mais que a busca por constantes, explicitam o pluralismo ontológico das manifestações aqui apresentadas.

\section{Um só ou vários botos?}

A experiência da qual partimos se conecta com as atividades do Instituto Bicho D’água, que atua no estudo e conservação de mamíferos aquáticos na região da Ilha de Marajó, no Estado do Pará, com um viés socioambiental. A costa leste da ilha de Marajó é uma região de estuário onde as águas da bacia amazônica desaguam no Oceano Atlântico, um sistema ecológico regido pelas marés no qual água doce e água salgada se alternam constantemente. O Instituto, sediado na cidade de Soure, tem como objetos de pesquisa quatro espécies que ocorrem na região. Duas são de peixes-boi: o peixe-boi-da-Amazônia (Trichechus inunguis) e o peixe-boi-marinho (Trichechus manatus) ${ }^{2}$. As duas outras são espécies de botos, ou golfinhos de rio: Sotalia guianensis, conhecido como boto-cinza ou tucuxi; e Inia araguaiaensis, conhecido na região amazônica como boto-vermelho, ou boto-malhado, e no Sudeste do Brasil como boto-cor-de-rosa, ou boto-rosa ${ }^{3}$.

As pesquisas desenvolvidas envolvem monitoramento de encalhes de mamíferos aquáticos, coleta de amostras biológicas, trabalho com a comunidade local e observação direta dos animais em vida livre. Tudo isso gera informações sobre distribuição, comportamento e ecologia das espécies em questão. A interação entre mamíferos aquáticos e pescadores é um tema bastante estudado ao redor do mundo no âmbito da biologia da conservação. No caso do projeto desenvolvido pelo Instituto Bicho D’água, os impactos da atividade pesqueira sobre a vida dos mamíferos aquáticos são avaliados contando com a colaboração das comunidades locais, que são convidadas a participar da pesquisa, discutir resultados e propor recomendações para minimizar possíveis conflitos. A participação dos pescadores é fundamental nesse contexto, seja para a localização e registro do movimento das espécies, seja para a troca de conhecimentos acerca da interação dos animais monitorados com os barcos e artefatos de pesca.

Entre agosto e setembro de 2016, em uma experiência de pesquisa colaborativa relacionada a essas atividades ${ }^{4}$, tivemos uma série de conversas com moradores e frequentadores da Reserva Extrativista Marinha de Soure (Resex de Soure), uma unidade de conservação que conjuga conservação ambiental e práticas extrativistas. Essas conversas foram gravadas em vídeo e posteriormente transcritas, com a devida autorização das pessoas envolvidas. Elas não tinham uma estrutura pré-definida; a ideia era identificar, tendo em vista um aprofundamento futuro, temas relacionados às práticas de pesca, à ecologia da ilha e à interação dos moradores da região com a vida marinha.

O primeiro registro que trazemos desse experimento provém de um encontro nosso com a bióloga Renata Emin, do Instituto Bicho D’água, e dois pescadores em uma pequena vila nos arredores de Soure. No material filmado, estes últimos nos
2 No passado, o peixe-boi foi intensamente caçado na Amazônia brasileira, até se tornar muito raro. Sua conservação é um tema complexo que pretendemos abordar em futuros trabalhos.

3 Sobre estes animais em específico, é mister ter em mente que há um debate científico em curso sobre a existência de duas espécies diferentes de boto-rosa, Inia geoffrensis, que habita a maior parte da bacia amazônica, e Inia araiaguaiensis, residente do Rio Araguaia (Ferreira da Silva et al., 2014). Falar sobre essa divisão dos botos-rosa nos desviaria do caráter principal deste estudo. Contudo, é um belo exemplo que tampouco o estatuto científico destes animais - isto é, na ontologia euroamericana - é fixo e imutável.

4 A pesquisa colaborativa teve início em agosto de 2016, com uma experiência de campo conjunta de duas semanas realizada a partir de uma parceria entre o Instituto Bicho D’Água e o Laboratório de Estudos Socioambientais, ligado ao Departamento de Ciências Sociais da PUC-Rio. Uma colaboração mais antiga entre a bióloga Renata Emin e o antropólogo Orlando Calheiros foi o que propiciou a parceria (Calheiros, 2009), sendo que ambos contribuíram posteriormente com comentários e na revisão do presente artigo. $\mathrm{A}$ experiência de 2016 foi também o primeiro passo para uma pesquisa de campo de maior fôlego desenvolvida por um de nós na Ilha do Marajó, vinculada ao Mestrado em Antropologia Social pelo Museu Nacional-UFRJ. A dissertação, concluída recentemente, teve como tema principal a Encantaria marajoara (Vasconcelos, 2020). 
conduzem através da vegetação de manguezal para mostrar-nos como o regime das marés pode fazer com que uma floresta alta de manguezal em pouco tempo se converta em praia e vice e versa. Desta forma, demonstram que a fixação das residências nessa região da ilha é sempre negociada com os diversos elementos da paisagem. A conversa é ambientada no quintal da casa de Chalopa, antigo colaborador do Instituto. O segundo pescador presente é Nilson, membro do conselho deliberativo da Reserva Extrativista de Soure ${ }^{5}$. No decorrer da conversa, ambos se mostram preocupados com os cuidados necessários para a reprodução dos peixes e com o modo como os recursos locais estão ameaçados por modalidades predatórias de pesca, praticada por gente de fora. Chamam atenção, nesse sentido, para o que percebem como uma diminuição progressiva dos peixes ao longo das últimas décadas.

Logo, o assunto se volta para os botos:

Chalopa: O boto tucuxi é um boto manso. É um boto mansinho.

Nilson: O tucuxi era o boto que sinalizava pro pescador quando tinha peixe. Era muito peixe! Está difícil agora... O pessoal via ele pulando e arredava ali no meio, porque era justamente onde estava a quantidade de peixe maior.

Nilson explica que esse boto, de menor porte, fica muitas vezes preso nas redes de pesca - fato que é reconhecido por especialistas como uma das mais sérias ameaças para sua conservação. Mesmo não sendo pescados diretamente (sua carne é considerada "remosa", não comestível), os animais neste caso podem acabar morrendo como efeito colateral da atividade pesqueira.

O contraste entre os dois tipos de boto é evidente na fala de nossos interlocutores:

Chalopa: Todo mundo tem receio de boto malhado. É uma coisa muito inteligente pra ser um peixe. É muito inteligente. Você coloca uma rede ele despesca (sic) tudinho. (...) O que mexe na rede é o malhado.

Nilson: Ele mexe na rede, mexe com a mulher dos outros, mexe com as meninas novas. Esse aí que é o cara. Ainda vai na festa pra tomar a mulher dos outros [risos].

Chalopa: Ele gosta de mulher, ainda mais quando ela está nos dias dela. Meu pai do céu, só falta alagar a canoa quando a mulher vai dentro! Ele bufa do lado da canoa e só falta embarcar na canoa.

Como em muitas outras partes da Amazônia, no Marajó o boto-malhado, ou vermelho, é especialmente cercado de precauções e distanciamentos por seu
5 A criação da Reserva Extrativista Marinha de Soure, em 2001, está ligada às demandas das comunidades de pescadores extrativistas locais, principalmente caranguejeiros, a partir da preocupação com os impactos da pesca predatória. Disponivel em: http://www. icmbio.gov.br/portal/images/ stories/plano-de-manejo/plano de manejo resex marinha de soure v19.pdf. Acesso em: 3 dez. 2018.

60 termo tucuxi é usado neste caso para designar o boto que frequenta a região, Sotalia guianensis, mais frequente em regiões costeiras. Boto-cinza e boto-preto são outros nomes comuns para esta espécie, enquanto tucuxi é usado com mais frequência para Sotalia fluviatus, a espécie que habita a maior parte dos rios amazônicos. 
potencial sedutor e transformacional. Ao longo dos rios, em diferentes regiões, a ideia de que ele é atraído por mulheres menstruadas é recorrente. Em quase toda a parte é possível se encontrarem também relatos sobre sua manifestação como um homem sedutor, sempre vestido de branco. Este tipo de narrativa pode suscitar diferentes abordagens, mas queremos chamar atenção neste ponto para aquilo que vemos como um desafio difícil no campo da etnoecologia. Este desafio diz respeito, no nosso entendimento, ao problema do encontro entre modos de conhecimento, ou cosmologias. Ou seja, o problema de como comparar ou colocar em relação conhecimentos provenientes de campos científicos ou acadêmicos e conhecimentos provenientes de populações tradicionais.

Entendemos que uma tendência difícil de ser evitada, neste âmbito, é a produção de uma separação entre, de um lado, a dimensão prática - empírica, vivida - das experiências e saberes locais e, de outro, a dimensão "cultural" - cosmológica, religiosa - dessas mesmas experiências. Isso significaria, por exemplo, que uma parte de nós ficaria com a primeira parte da frase de Nilson, que diz que o boto "mexe na rede" do pescador, mas abandonaria a segunda parte, quando ele afirma que "mexe com a mulher dos outros"; tudo que é dito daí por diante seria então atribuído ao plano do anedótico. O restante de nós iria pelo caminho inverso, abandonando a ecologia dos rios e os regimes de pesca e se restringindo apenas ao campo dos significados socioculturais e religiosos do boto.

Em busca de uma alternativa a essa desgastada dualidade, o que nos importa é menos a forma como os pescadores representam a situação do que o modo como refletem sobre ela a partir de sua interação com os botos, com os projetos de pesquisa e os cientistas, com a mudança dos tempos. Entendemos, nesse sentido, que tanto os botos quanto os vários seres humanos que convivem com eles adquirem suas formas particulares a partir do modo como suas relações se desdobram.

\section{Ecologia, sociologia, cosmologia: irreduções \\ 3.1 Botos ameaçados}

Como vimos acima, a conservação de mamíferos aquáticos na Ilha de Marajó envolve a interação desses animais com as atividades humanas. Barcos e artefatos de pesca artesanal (com maior agressividade no caso da pesca industrial) fazem parte do mundo vivido dos botos, e podem representar graves ameaças a eles em determinadas situações, como nos casos em que ficam presos nas redes. Além disso, eles são vistos muitas vezes como rivais, podendo sofrer retaliações por parte dos pescadores. O conflito entre humanos e botos é, no entanto, ambivalente. Principalmente pelo fato de que estes últimos são temidos e cercados de tabus nos rios amazônicos.

Os poderes mágicos atribuídos aos botos no que se refere à sedução amorosa, por exemplo, tomam a forma de feitiços e unguentos comercializados em grandes cidades brasileiras. Uma pesquisa recente confirmou que há um comércio regular de produtos contendo órgãos genitais e olhos de botos, vendidos como amuletos e simpatias de amor em mercados de Belém e outras capitais da região norte do Bra- 
sil. Além disso, partes de suínos são usadas para falsificar produtos deste tipo, o que já foi documentado no Rio de Janeiro, no sudeste do país (Siciliano et al., 2018).

A captura, direta ou acidental, pode ser incluída em uma série de ameaças que pairam particularmente sobre os botos do gênero Inia. Entre elas estão a fragmentação das populações causada por represas hidrelétricas, a poluição dos rios com mercúrio e outros rejeitos ligados à atividade da mineração, projetos de irrigação para agricultura, que retira água dos rios, interação com as atividades de pesca, ou atividades de turismo interativo com os botos ${ }^{7}$. Usando como referência uma pesquisa do Laboratório de Mamíferos Aquáticos do Instituto Nacional de Pesquisas da Amazônia (INPA) ${ }^{8}$, o boto-vermelho (Inia geoffrensis) foi classificado, em novembro de 2018, como "em perigo de extinção" na Lista Vermelha de Espécies Ameaçadas da União Internacional para Conservação da Natureza e dos Recursos Naturais (IUCN) ${ }^{9}$. O boto-malhado (I. araguaiaensis) ainda não teve seu estado de conservação avaliado.

As duas espécies do gênero Sotalia - Sotalia guianensis e Sotalia fluviatilis -, por sua vez, estão classificadas atualmente entre aquelas com "dados insuficientes" para a definição de seu status de conservação. Isso decorre da quantidade limitada de informações sobre as populações, ecologia e taxas de mortalidade, entre outros fatores.

No que se refere às práticas de campo científicas, nos últimos anos tecnologias envolvendo o uso de drones e pequenos dispositivos com sistema GPS, conhecidos como $\operatorname{tags}^{10}$, têm permitido a realização de estudos mais aprofundados sobre ecologia dos rios amazônicos, incluindo estimativas populacionais dos botos. Quanto mais se sabe sobre eles, porém, ao que parece, mais se revela a gravidade da situação em que se encontram.

A pesquisa citada acima, realizada pelo INPA em uma área protegida da Amazônia, mostrou, entre outras coisas, que, no caso do boto-vermelho, uma modalidade de caça relativamente recente tornou-se um fator importante de declínio da espécie, com o uso de sua carne e gordura como isca para a pesca de uma espécie local de bagre (Silva et al., 2018). Esta espécie, conhecida regionalmente como piracatinga, ou urubu-d'agua, quase não é consumida no Brasil, mas tornou-se valorizada comercialmente na Amazônia nos últimos 15 anos, a partir de uma demanda do mercado colombiano. No contexto onde essa atividade surge, os autores observam que "alguns pescadores matam deliberadamente botos emaranhados, não só pela percepção de competição por peixes, mas também por causa dos danos causados aos artefatos de pesca” (Idem) ${ }^{11}$. O que marcam como um corte temporal, a partir daí, são as mudanças trazidas pelo uso da carne dos botos, que seria descartada, como isca para a piracatinga, o que parece ter levado a uma alteração no jogo de forças local entre humanos e cetáceos.

A situação à qual os autores se referem repercute, neste caso, em uma espécie de percepção em que os perigos e ameaças em jogo se desdobram simetricamente em aspectos caracterizados separadamente como ecológicos ou culturais. $\mathrm{O}$ que chama atenção, neste caso, é o lado torpe desse novo tipo de pesca, motivada pelo interesse puramente comercial de um peixe que nem sequer é consumido
7 Ver, a esse respeito: $\underline{\text { http:// }}$ amazonia.org.br/2018/12/a-dois-passos-da-classificacao-de-extinto-boto-vermelho-entra-paralista-vermelha-da-iucn/. Consultado em 17/01/2019.

8 A pesquisa, coordenada pela bióloga Vera da Silva, constatou a redução constante do número de animais ao longo do monitoramento, realizado por mais de 20 anos, entre 1994 e 2017, na área da Reserva de Desenvolvimento Sustentável de Mamirauá e no entorno (Silva et al., 2018).

9 Disponivel em: https:// www.iucnredlist.org/species/10831/50358152. Acesso em: 17 jan. 2019.

10 Esses dispositivos são fixados nos corpos dos animais, em geral nas nadadeiras dorsais, gerando dados detalhados sobre seus movimentos em baixo d’água. 
no Brasil. Do ponto de vista ecológico, temos uma espécie ameaçada e endêmica de cetáceo sacrificada para a captura de uma espécie comum de bagre. $\mathrm{O}$ artigo descreve, de forma análoga, uma situação em que o ethos tradicional amazônico tende a ser substituído por uma ideologia de exploração inconsequente dos recursos naturais. Nesse sentido, Silva e outros observam a respeito das tradições locais, que: "Até as últimas décadas, o boto foi protegido, em certa medida, por lendas e superstições, e muitas vezes liberado pelos pescadores quando encontrado ainda vivo em suas redes" (Ibidem, grifo nosso).

De uma perspectiva estritamente conservacionista, os tabus culturais interessam muitas vezes apenas em função dos resultados práticos que produzem, ou, neste caso, na medida em podem fornecer algum tipo de ameaça ou de proteção para uma espécie em perigo. "Lendas e superstições", no entanto, não são categorias inócuas, e podem nos fornecer pistas para o agenciamento conservacionista e as práticas tradicionais envolvidas na relação com os botos. A perspectiva que sustenta o argumento é compreensível se levarmos em consideração a necessidade da luta por políticas que respondam ao processo gravíssimo da extinção de espécies associado às atividades econômicas desenvolvidas atualmente na Amazônia brasileira. Entendemos, entretanto, que a redução da questão a uma questão ecológica stricto sensu, nos termos supracitados, apresenta desdobramentos antropológicos potencialmente problemáticos.

Tematizando as controvérsias socioambientais em torno dos caribus, ou renas (Rangifer tarandus), em Labrador, no Canadá, Mario Blaser aponta para o tipo de ressignificação, ou domesticação, dos conhecimentos locais que tende a ocorrer quando estes animais são incorporados em políticas públicas e traduzidos nos termos do gerenciamento dos recursos naturais. $\mathrm{O}$ conhecimento dos caçadores a respeito dos rebanhos de caribus, no caso canadense, é separado, no que se refere à elaboração de políticas ambientais, da dimensão em que se manifesta o espírito dono dos animais, entidade com a qual os caçadores nativos interagem e a partir da qual concebem suas relações com os animais caçados. A controvérsia socioambiental gerada em torno da situação envolve uma série de conflitos entre ambientalistas, governo e populações nativas (Blaser, 2018).

$\mathrm{Na}$ Amazônia brasileira, Mauro Almeida descreve a troca de conhecimento entre cientistas e ribeirinhos do Alto Juruá ${ }^{12}$, no Acre, em termos dos "conflitos ontológicos” que se estabelecem entre eles e dos "acordos pragmáticos” em torno dos quais são capazes de interagir (Almeida, 2013). A ontologia naturalista da ecologia científica, de um lado, e o regime de reciprocidade envolvido nas relações dos ribeirinhos com a caça, de outro, partem de premissas e compreensões diferentes acerca das relações entre os seres vivos suas interações. Referindo-se às prescrições e cuidados dos caçadores diante do espírito "dono" ou "mestre" dos animais, Almeida afirma que "caiporas são partes de redes", e que essas redes envolvem "conexões não hierarquizadas de pessoas, animais, instrumentos de caça, partes da floresta e partes da casa" (Almeida, 2013, p. 21).

O caso dos botos se dá em um contexto sociocosmológico análogo, sendo que os pescadores amazônicos, em geral, e do Marajó, em particular, observam uma
12 A Reserva Extrativista do Alto Juruá foi a primeira deste tipo no Brasil. Ver, a esse respeito, Carneiro da Cunha e Almeida (2009). 
série de preceitos em relação aos encantados, donos, entidades do fundo, as quais norteiam suas interações com o ambiente e com os outros seres vivos. Embora as ciências da conservação não tenham dificuldade em levar em conta o conhecimento prático dos habitantes locais a respeito dos cardumes e movimentos dos botos - e muitas vezes precisem mesmo desse tipo de conhecimento -, elas tendem, entretanto, a descartar a dimensão cosmológica das interações em curso. As entidades a serem levadas em conta são subordinadas, então, a uma cosmologia situada, a científica; o que implica em uma recusa de outras entidades, tratadas como anedóticas, residuais ou mesmo irracionais.

Trata-se do tipo de redução que pretendemos evitar aqui, sem deixarmos de lado as questões envolvidas nas práticas conservacionistas e na produção de conhecimento científico. A proposta de levar em conta simultaneamente os aspectos ambientais e os aspectos socioculturais de uma questão remete ao que Bruno Latour (1984) chamou, no âmbito do estudo das práticas científicas, de "princípio de irredução". Norteados por esse princípio, a saída que vislumbramos para o impasse, neste caso, é também uma saída que poderíamos chamar de ecosófica, no sentido que o termo é empregado por Félix Guattari em As três ecologias (1990), como uma articulação necessária e urgente entre a ecologia do ambiente, a ecologia do social e a ecologia da subjetividade, ou da mente. Formulados a partir dessa tripla articulação, tanto os processos de degradação quanto os processos de resistência e preservação se conectam aos agenciamentos subjetivos individuais e coletivos nos quais são potencialmente capazes de se desenvolver e proliferar.

Podemos elaborar, nesse sentido, uma reflexão sobre diferentes registros das interações em curso, ou diferentes registros ecológicos. No que se refere à "ecologia do ambiente", encontramos interações entre humanos e botos envolvendo competição e processos de extinção. No entanto, botos e bagres, pescadores e cientistas, empreendedores e ambientalistas, estão todos implicados na trama complexa de relações que compõem a vida rios da Amazônia. $\mathrm{O}$ ambiente repercute no social, assim como nos processos de construção da subjetividade, ligados neste caso a uma dimensão espiritual.

Ao considerarmos a abordagem das três ecologias proposta por Guattari, apesar das divisões marcadas entre esses planos de experiência, eles se encontram implicados uns nos outros de forma transversal, ou seja, cada domínio pode, a qualquer momento, ser atravessado pelo outro. As experiências da ecologia ambiental, social e subjetiva são tratadas em sua reciprocidade. Isso implica que qualquer explicação que se apresente enquanto verdade final sobre a experiência seja vista como uma redução da complexidade dos agenciamentos envolvidos.

\subsection{Botos ameaçadores}

No que se refere ao reducionismo ecológico que buscamos evitar acima, estamos falando, nos termos propostos por Bruno Latour em Jamais fomos modernos (1991), de uma "naturalização" do fenômeno, isto é, na adoção de uma perspectiva ligada aos fenômenos biológicos, ou ecológicos, na qual há pouco espaço para elementos culturais, espirituais ou religiosos. Mas Latour aponta, por outro lado, 
para a possibilidade de outro tipo de reducionismo via "sociologização", ou seja, a redução de um fenômeno à sua dimensão estritamente sociopolítica, vinculada às relações de poder e dominação presentes em contextos regionais. Neste caso, as interações biológicas é que tendem a ser descartadas como puramente mecânicas ou funcionais.

Um exemplo disso pode ser visto em algumas discussões em torno da lenda do boto. Sua imagem como um homem branco que seduz jovens mulheres pode funcionar, neste contexto, como "uma memória explícita da colonização", como argumenta Deborah Lima (2014, p. 193). Situações de violência e abandono das mulheres na Amazônia se conectam de diversas formas, neste contexto, com relatos de encontros com botos, como fica evidente, por exemplo, na coluna publicada na Carta Capital, em 2017, pelas juízas Elinay Melo e Nubia Guedes, intitulada "Não foi boto sinhá: a violência contra a mulher ribeirinha"13. As autoras argumentam, nesse sentido, que as histórias regionais do boto reforçam aspectos de uma sociedade patriarcal, machista e misógina, "escondendo por trás de tudo isso anos e anos de violência dirigida às mulheres, assim como altos índices de estupro, muitas vezes no seio familiar, nos rincões da Amazônia”.

O registro em cartório de crianças órfãs como "filhos do boto" é um fato comum em toda a região, funcionando muitas vezes como forma de justificar socialmente o abandono paterno ou mesmo a violência contra a mulher. É certo que essa violência compõe o cotidiano de vários grupos, muitas vezes minoritários, sendo que o crescimento populacional e a expansão da urbes são realidades presentes para muitos deles. Trata-se de uma chave de leitura importante para o entendimento dos processos locais. Não acreditamos, contudo, que decorra daí que o colonialismo e a violência de gênero expliquem os múltiplos relatos e narrativas de encontros com os botos, ou que essas narrativas possam ser definitivamente reduzidas a artifícios para esconder tais atos - mesmo sabendo que elas são, de fato, utilizadas desta forma em diversos contextos.

Como alternativa, nos recusamos inicialmente a adotar a perspectiva da ecologia científica, do boto como espécie ameaçada, como fundamento ou contexto de efetuação sobredeterminante em relação aos outros contextos possíveis. $O$ mesmo vale para a perspectiva das relações de poder e da violência de gênero na Amazônia. Nossa proposta é que, ao invés de funcionarem como chave última de explicação, essas duas perspectivas sejam entendidas como elementos em um conjunto de transformações que não são redutíveis entre si.

A proposta nos remete à ideia da "equivocidade controlada" que Viveiros de Castro propõe como fundamento para a tradução (2015, p. 87). Um dos fundamentos do conceito do perspectivismo ameríndio, desenvolvido pelo autor, diz respeito ao fato de que as ontologias amazônicas postulam a diferença, em vez da identidade, como o princípio relacional. Neste caso, "o equívoco não é o que impede a relação, mas aquilo que a funda e propele”, como diz Viveiros de Castro (2015, p. 91). Ao invés de ser entendido como erro ou ilusão, oposto à verdade, o equívoco opõe-se, nesse sentido, ao pressuposto da existência de um sentido único e transcendente que o anularia.
13 Disponivel em: $\underline{\text { http:// }}$ justificando.cartacapital.com. br/2017/02/01/nao-foi-boto-sinha-violencia-contra-mulher-ribeirinha/. Acesso em: $18 \mathrm{dez}$. 2018. 
O que temos em vista é um exercício inspirado neste tipo de teoria da tradução, no qual o boto possa ser descrito em seu processo mesmo de transformação. Voltaremos ainda a esta questão. Antes disso, porém, nos cabe acrescentar ainda ao nosso tema uma camada crucial, que diz respeito ao aspecto cosmológico do boto enquanto encantado. Na Encantaria Amazônica, os botos são entidades que se manifestam de diversas formas entre nós, humanos. Procuraremos mapear a seguir algumas dessas manifestações.

\section{O boto encantado e suas transformações}

Durante nossa breve experiência de campo conjunta na Ilha de Marajó, acompanhamos o Círio de São Sebastião, uma procissão anual em que uma pequena imagem do santo católico é levada em carreata da área urbana de Soure para as pequenas comunidades pesqueiras de Caju-Una e Céu, localizadas na área da Reserva Extrativista. O destino da imagem, ao final do cortejo, foi a casa de um antigo morador do povoado chamado Seu Pombo, anunciado sob o título de "presidente de honra vitalício" da festividade pelo locutor do carro de som que seguia a caravana. Durante a conversa que registramos com ele, no dia seguinte ao evento, Seu Pombo nos explica que a comunidade onde estávamos era a terceira vila de Caju-Una, sendo que as duas primeiras a maré tinha levado. Ele mesmo morava na localidade havia mais de trinta anos, tendo chegado na época da segunda vila (hoje tomada pelo mar) e se transferido mais tarde para a atual. O caráter cambiante da paisagem e o desafio trazido por esse ambiente indômito enquadram o diálogo.

No trecho a seguir, Seu Pombo nos fala sobre os botos:

Aqui no rio tem muito boto. Tem o tucuxi, tem o malhado... tem muito aí no rio. Até onde tem os peixes, eles estão atrás pra comer, eles andam atrás dos peixes no fundo. Então tem uma sardinha assim [mostra o tamanho de um palmo] - ela é até beneficiada na região de Salina, São Caetano. Pra aí tinha uma fábrica. Eles beneficiam essa sardinha em sardinha em lata. Então, essa sardinha, os peixes se apoderam dela pra comer. Junta muito peixe, (...) a sardinha chama os peixes grandes pro boto pegar. Vem bagre, serra, sarda, tudo vem. É assim que é a vida do boto. Você vê ele, é um avião na água.

Tanto a ecologia dos rios quanto a economia pesqueira, como podemos ver, fazem parte da vida do boto. As interações entre ele e os diversos peixes se articulam, na fala de Seu Pombo, em uma trama de interações da qual faz parte também a produção de sardinhas em lata. Na continuação da conversa, perguntamos:

E essa história que o pessoal fala, que o boto é namorador, o que o senhor acha disso?

Seu Pombo: É sim senhor. Ele é. Já vi contarem muito caso. Conheci pessoas que já morreram... Mulher em beira de rio não é bom estar. Viver em beira do rio, aqui. Ele vem na fisionomia do marido e se serve da mulher. Ele é 
safado, é jangadeiro.

O senhor conhece o Mario Couto? Deputado Mario Couto? De Salvaterra. Aquele que está em Brasília, é deputado? ${ }^{14}$.

Diante de nossa negativa, ele prossegue:

Procure saber quem é. Ele é filho daqui do Marajó, de Salvaterra. Então, tinha um rapaz - que morreu novo - amigo dele, forte, o Beja, lá da Beirada, Caldeirão. Era amigo dele. Ele vinha de Brasília e embarcavam num lanchão muito lindo e confortável, e iam pescar. Lá pra Guia, um ponto de pesca. Foram pescar, foram pra lá e apareceu um boto. Ele começou a assobiar pro boto; e ofender. O rapaz disse: Mário, não mexe com ele! Você não sabe com quem tu tá mexendo. Mas ele não ligou, porque esse pessoal rico não acredita em certas coisas. E lá adiante tem uma porção de cobra grande, nesse lugar, chamado Mucunã. É fundo, feio... E diz que, quando o Mario Couto viu, chegaram pra mais de mil botos e cercaram a lancha dele. Cercaram pra meter no fundo a lancha. E iam meter. Olha, ele ligou o motor da lancha e se empurrou. Não foi mais lá.

Há um aspecto das relações com os botos que precisa ser respeitado por quem navega em determinados lugares, e o desrespeito a eles traz consequências para quem ofendê-los. Tanto a ecologia quanto a economia, neste caso, se relacionam com uma dimensão do cosmos que lhes confere sentido, sendo que os preceitos a serem observados valem para todos, incluindo os ricos e poderosos. "Não se mexe com essas coisas”, diz Seu Pombo. E conclui:

Porque tem muito mais gente, encantados, do que nós em cima da terra. Tem. Então, pra andar nesse mato aqui, a gente tem o costume de pedir licença: Minha vó, me dê licença de eu vir dar uma pescada, eu sou um homem pobre, vim aqui - pede o consentimento. Porque eu sou dono disso aqui [aponta para sua própria casa], mas existem outros donos. Dono do Igarapé, fulano de tal, tem. Tem sim senhor. Tem porque eu vejo. Eu sou um homem que eu vejo as coisas.

O depoimento nos remete, neste ponto, ao campo da Encantaria Amazônica. Os encantados, suas moradas e lugares de encante estabelecem certas fronteiras, mas elas não se parecem com limites intransponíveis. A transição parece ser muito mais fluida, e por isso mesmo perigosa. A fronteira funciona aqui ao mesmo tempo como um sinal de alerta, uma postura comportamental e um preceito ético. Pedir licença é um ato necessário nessa "cosmologia cabocla” (Figuras 1 e 2). Devemos respeitar os entes que habitam outras moradas, todos esses que são "muito mais em cima dessa terra" do que nós. E os limites estão dispostos de diferentes maneiras, a depender da perspectiva adotada para lidar com tais forças.
14 Mário Couto cumpriu quatro mandatos consecutivos como Deputado Estadual do Pará (de 1990 a 2006), tendo presidido também a Assembleia Legislativa do Estado. Atualmente está vinculado ao PP (Partido Progressista). Entre os fatos mais marcantes de sua carreira política estão os dois pedidos de Impeachment de Dilma Rousseff que apresentou na Câmara. Disponível em: https://pt.wikipedia.org/wiki/ Mário Couto. Acesso em: 19 dez. 2018. 


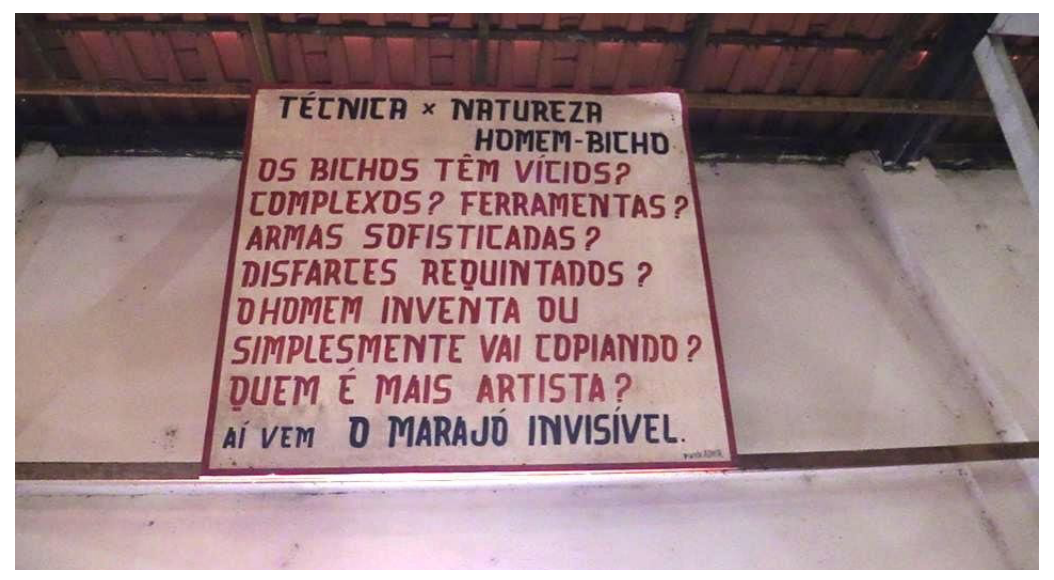

Figuras 1 e 2: Placas no Museu do Marajó, localizado em Cachoeira do Arari (fotos: Kauã Vasconcelos).

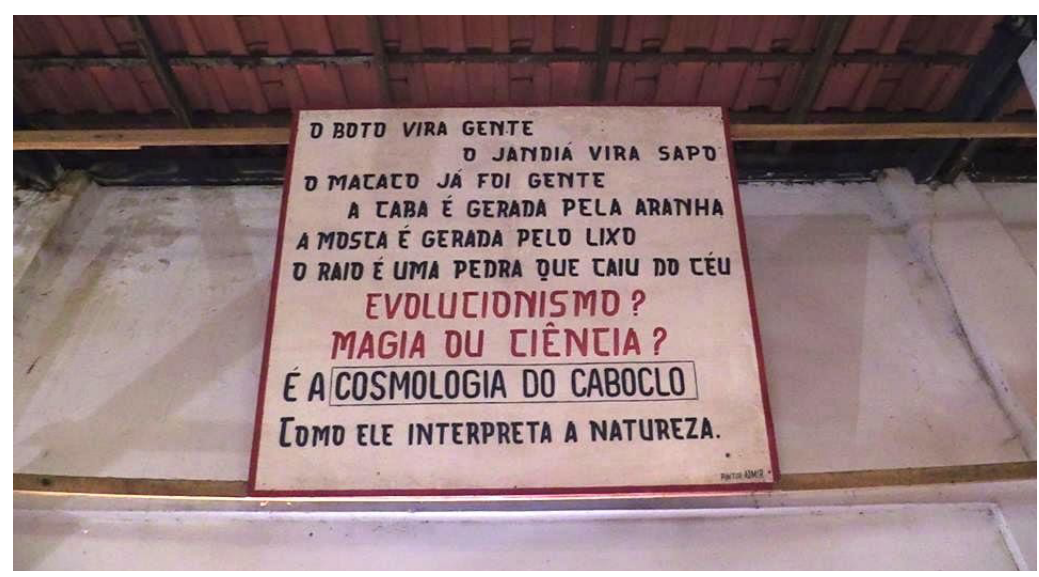

Florêncio Vaz Filho afirma que "o universo amazônico tem uma realidade material e outra espiritual bem conectadas e ordenadas em quatro níveis ou dimensões”. Essas seriam (1) a das águas, (2) dos espíritos, ou bichos da terra, (3) do mundo físico e, por fim, (4) o céu e o inferno cristãos. Os espíritos da mata e os das águas (do fundo), de acordo com ele, são os que têm relação direta com a defesa dos elementos da natureza: "As histórias dos caçadores que conversam e fazem trocas com o Curupira - ou Caipora - (geralmente tabaco e cachaça) são um exemplo de uma convivência pacífica possível entre humanos e a natureza, cuja base será sempre o respeito" (Vaz Filho, 2013).

Em seu famoso estudo sobre a vida religiosa de uma comunidade amazônica, publicado em 1955, Eduardo Galvão nos apresenta, em seu capítulo sobre os "bichos visagentos", o "reino encantado" que existe no fundo dos rios e dos igarapés. Mundo submerso que guarda semelhanças com uma cidade, "onde tudo brilha". Um dos seus habitantes é o boto. Os botos são evitados pelo temor de serem encantados. Teme-se sua malineza, ou seja, sua capacidade de punir aqueles que os ofendem. Longe de apenas responderem às ofensas, porém, os botos são conhecidos pelo poder de sedução. "É frequente sua aparição como um jovem atraente que seduz as mulheres” (Galvão, 1955, p. 94). De acordo com o autor, esse jovem atraente por vezes surge como um homem vestido de branco, ou, quando a mulher é casada, pode assumir a forma de seu marido (o mesmo que nos diz Seu Pombo).

Caso as relações com o encantado não sejam interrompidas, a mulher pode emagrecer, "amarelar", ficar mofina, inclusive até vir a padecer. Outras narrativas 
apontam para a possibilidade da mulher ter um filho do boto, sem deixar de lado o risco que essa gravidez traz para a vida de ambos. Por tudo isso, os botos são constantemente evitados por aqueles que contam esses casos, o que assinala também o perigo para quem ferir, arpoar ou matar um deles ${ }^{15}$. Somente caso sejam achados mortos - diz Galvão - é que as partes de seu corpo costumam ser usadas como patuás (talismãs), ou para o preparo de milongas, ou feitiços (1955, p. 97). O boto pode se manifestar, de acordo com o autor, ora como espírito auxiliar nos trabalhos espirituais, ora como espírito perigoso e predador.

Observamos este tipo de ambiguidade entre perigo e aliança na conversa que transcrevemos na primeira parte deste artigo, na qual o tucuxi é apontado como um potencial ajudante e o boto-malhado como um antagonista que "mexe na rede" dos pescadores. Galvão distingue, nesse mesmo sentido, o boto "grande", vermelho ou malhado, e o tucuxi. Quando opõe esses dois, coloca o tucuxi como aquele que "ajuda aos afogados empurrando-os para as praias" e ainda aquele que tem o "poder de afugentar os 'vermelhos' quando estes atacam as canoas ou nadadores" (1955, p. 92-93). Ainda de acordo com ele, normalmente são os botos vermelhos aqueles associados aos encantados.

É interessante notarmos, entretanto, que o contraste em questão pode nem sempre se referir a uma diferença entre espécies. Em trabalho publicado meio século depois de Galvão, Candace Slater relata o seguinte:

Em aparente contradição direta com as afirmações feitas logo antes sobre a natureza perigosa, quando não claramente malévola, do Boto, alguns pescadores falam entusiasticamente dos benefícios trazidos por determinados Botos para eles e para seus companheiros. "Quando é verão e há praias em toda parte, pescamos junto com o Boto", explica um homem mais velho em Faro. "Tudo que temos que fazer é acender a lanterna e ele vem nos ajudar como um cão de caça. Sim, aquele grande Boto vermelho nos traz uma porção de peixes" (Slater, 2001, p. 103) ${ }^{16}$.

A distinção mais dualista parece não se sustentar tão rigidamente, sendo que ambos os botos podem ser tanto auxiliares quanto capazes de infringir danos sem um motivo explícito. Em todo caso, o que chama atenção é o caráter ambivalente dessas relações.

Heraldo Maués reforça esse mesmo caráter ao observar que os botos podem tanto "curar e praticar o bem", como "provocar doenças e malinar as pessoas" (Maués, 2006, p. 21). O boto enquanto encantado é descrito por ele como uma "gente do fundo", uma "pessoa imitando bicho". "Imitar" aqui não no sentido performático. Um interlocutor de Maués, pajé e pescador aposentado, afirma que a "gente do encante se vira em tudo, se vira numa cobra, num boto, num peixe [...]. Bicho é isso que se fala, mas o encantado se vira em tudo, e o bicho muitas vezes é uma gente do encante" (Ibidem, p. 20). Chamando atenção para o perigo inerente ao encontro com esses seres, Maués traça uma interessante analogia entre a figura do vampiro e a do boto. Além de seduzir as mulheres através de uma
15 Uma notícia veiculada pelo periódico Voz do Norte, em 2013, narra o caso de um jovem "perturbado" depois de atirar em um boto. Após ter as redes rasgadas e os peixes comidos pelo bicho, Valdecir Souza, que estava acompanhado do primo, decidiu atirar contra ele. Logo sua canoa ficou cercada de botos que tentaram inundar a embarcação. O jovem passou a sofrer dores e ter visões de um homem vestido de branco no meio do rio, em cima de uma pedra. Teve que ser contido pela família para que não se lançasse ao fundo. Disponível em: http://www.juruaonline. net/acre/encantado-pescador-atira-em-bota-fica-perturbado. Acesso em: 20 dez. 2018.

16 É interessante notar que a colaboração entre golfinhos e seres humanos já foi descrita em diferentes lugares, entre eles a região no sul do Brasil. Ver a esse respeito o trabalho de Brisa Catão e Gabriel Barbosa sobre a pesca colaborativa da tainha em Laguna, Santa Catarina (Catão e Barbosa, 2018). 
conotação sexual, assim como nas histórias de vampiros, este último desvitaliza as mesmas drenando seu sangue ${ }^{17}$. A atração pelo sangue feminino se associa, no caso dos botos, especialmente à menstruação, tema que aparece em diversos autores comentados aqui.

Galvão observa, a esse respeito, que "o boto tem especial atração pelas mulheres menstruadas. Durante esse período as mulheres devem evitar viagens em canoa ou aproximar-se do rio ou dos igarapés" (1955, p. 93-94). Em um contexto bem diferente, tematizando o resguardo e a sexualidade na Amazônia peruana, Luisa Elvira Belaunde afirma que "a partir da perspectiva dos botos, o cheiro do sangue menstrual é um afrodisíaco poderoso”, operando sua transformação em humano (Belaunde, 2015, p. 553). Aqui, a alteridade se ramifica: alteridade interespecífica, alteridade dos seres sobrenaturais, alteridade entre ontologias. $\mathrm{O}$ inimigo devorador é de outro sexo, de outra natureza. A captura se dá dentro de uma relação em que um desvitaliza o outro, um consome o outro, drena suas forças para então assimilá-lo.

O trabalho de Belaunde traz uma perspectiva indígena da sexualidade não indígena na qual o boto desempenha um papel fundamental. Da mesma forma que habitam o imaginário sexual dos colonizadores, de acordo com ela, os grupos indígenas produzem ativamente uma perspectiva sobre as relações sexuais que são fruto, em parte, do contato com uma alteridade violenta e desmedida. Seguindo essa perspectiva, o caráter predatório do boto se transfere para sua sexualidade:

O eixo da questão não está na agressividade predatória dos botos, mas na sua sexualidade sem restrições e no desejo desenfreado que podem inspirar. O eixo da questão é a quebra do resguardo que coloca a mulher (e, menos frequentemente, o homem) na posição de presa dos botos (2015, p. 555).

A relação com os botos, neste caso, está intimamente ligada à construção do corpo indígena e ao encontro com alteridades que não respeitam o resguardo, gerando transformação para as redes de relações envolvidas. A importância do resguardo no mundo indígena é, podemos imaginar, tanto construtiva - no sentido de construir corpos e pessoas - quanto contradestrutiva, medida de precaução em um mundo composto de forças predatórias. Essa situação gera relatos que podem refletir o medo da captura, mas que podem também representar a prudência daqueles que, restituindo ao outro sua intencionalidade, podem evitar um encontro que já se desenha virtualmente em diversos sinais, como nos sonhos. Podemos perceber que, longe de uma narrativa romântica, o encontro com esses seres em geral não é visto como uma experiência desejável (mesmo que seja uma força desejante), muito pelo contrário.

Candance Slater transcreve, a respeito desse (mau) encontro, a seguinte afirmação: "Quem mata um Boto, muitas vezes fica panema. Não mata mais nada, só fica bom na mão do curador”. O termo amazônico panema, como ela explica, poderia ser traduzido genericamente como "falta de sorte" ou "azar"18. É algo que acomete o indivíduo, uma espécie de incapacidade para ação:
17 A comparação é arriscada, mas tem aspectos interessantes. Em uma conversa que tivemos com um pescador em Soure, este relatou que uma das técnicas utilizadas para afastar os botos das pequenas embarcações que saem para pescar a noite é a de colocar cabeças de alho penduradas na proa. De acordo com ele, os botos odeiam alho - o que nos remete mais uma vez aos vampiros.
18 Conceitos como Panema e Caipora fazem parte do que Mauro Almeida chamou, no contexto amazônico, de uma "economia ontológica da caça" (2013). 
Um homem pode se tornar panema em relação às mulheres, e o termo também pode indicar uma condição geral. (“Fiquei panema da vida, ou seja, “Fiquei sem sorte na vida”, pode dizer uma pessoa.) É, porém, mais comum que a palavra se aplique especificamente à capacidade de um homem para caçar ou pescar (Slater, 2001, p. 102).

Ela observa ainda que panema "pode ser o resultado do ato de caçar demais ou matar um animal considerado não comestível - como o boto" (Idem) ${ }^{19}$. Para a autora, as narrativas amazônicas sobre o boto "sugerem um mundo onde homens e mulheres não têm nem podem ter o controle (...), contrastando nitidamente com as representações nas quais os seres humanos têm sua silhueta pintada sobre uma paisagem natural” (Slater, 2001, p. 322). São histórias que revelam uma "incômoda continuidade" (Idem). Slater reúne diversas narrativas sobre o boto, sua transformação e metamorfose, seu potencial desestabilizador e sua força de resistência frente aos avanços de uma perspectiva moderna e desencantada do mundo que pretende não apenas banir sua existência, mas apontá-la enquanto farsa, crença, folclore:

\footnotetext{
"No passado", disse um organizador do Boi-Bumbá de Belém, que também é um chefe de culto afro-brasileiro, "os Encantados costumavam sair do rio e andar por aí de noite. Eu mesmo costumava vê-los nas ruas. Mas, com a passagem do tempo, as luzes e o tráfego estavam deixando-os malucos. Sim, pensando bem no assunto, há pelo menos dez anos que não vejo um Encantado em Belém” (Slater, 2001, p. 213).
}

Em uma perspectiva semelhante, Deborah Lima considera que as histórias do boto demonstram o poder de resistência do pensamento dos ribeirinhos diante de uma suposta "lucidez modernizadora" imposta historicamente pelos colonizadores na Amazônia. De acordo com ela, essas narrativas reafirmam dois aspectos: uma "definição de mundo não ocidental - o caráter fluído e mutável da relação entre a natureza e a cultura -, e a mensagem de crítica às transformações sociais” (Lima, 2014, p. 189), sendo essa crítica elaborada a partir da criatividade própria desse pensamento. É nesse sentido que o espírito ameaçador do boto se associa ao homem branco, ambos vetores de alteridade canibal na colonização amazônica. $O$ homem branco entendido enquanto outro; não metaforicamente, mas dentro de um arcabouço cosmológico em que corpos brancos, assim como o fazem corpos botos, metamorfoseiam-se como espíritos predadores.

\section{Considerações finais}

Argumentamos, como ponto de partida, que as relações nas quais os botos estão inseridos são atravessadas pela ideia da transformação. As interações entre botos e seres humanos na Amazônia são múltiplas, abarcando, para além de campos heterogêneos das práticas científicas e das relações socioeconômicas, suas manifestações cosmológicas e as práticas que as mesmas envolvem. Partindo
19 O tabu alimentar é analisado por Heraldo Maués (2006) como um fator central para a análise do simbolismo social e religioso dos botos. O tema remete a uma longa discussão sobre simbolismo animal e comestibilidade na tradição antropológica, a qual tem conotações interessantes mas que não desenvolvemos detalhadamente neste trabalho. 
deste princípio, de que o boto em si só existe como transformação, ou tradução, precisamos imaginar que isso não é algo que acontece apenas no campo das representações, porque desta forma teríamos que pressupor um referencial único para mais de um significado. Não seria correto, nesse mesmo sentido, pensarmos que há, por um lado, coisas unívocas, como as espécies, os rios, ou o clima, e, por outro lado, coisas passíveis de equívoco, como línguas, sistemas culturais ou categorias antropológicas. Isso significaria colocar o equívoco do lado da representação, enquanto a realidade se manifestaria sempre em um nível universal, objetivo, atuando como uma espécie de referencial fixo para diferentes pontos de vista.

Diante desta questão, buscamos cartografar diferentes transformações do boto em sua multiplicidade horizontal, isto é, sem estabelecer entre elas uma hierarquia ou um ponto de vista dominante. As manifestações do boto surgem, assim, como efeitos de uma rede complexa, permeada por diferentes práticas e significados. Não nos interessa, nesse sentido, a busca de uma mesma substância, ou essência, que se mantém em cada versão, mas antes traçar conexões, cartografar diferenças. Entendemos que este processo pode ser lido, como mencionamos anteriormente, na chave da ecosofia, formulada por Guattari, no sentido de que a ecologia dos rios nos quais os botos desempenham papéis chave se articulam com a ecologia histórica da colonização da Amazônia e com a ecologia do reino encantado, habitado por espíritos em devir animal. Cada uma dessas três ecologias traz consigo seus próprios mecanismos rituais e modos de ser e pensar, transversais em suas relações de aproximação e divergência.

Entendemos, assim, que o conjunto heterogêneo de transformações onde se encontram o boto "aquático", o animal que se locomove pelas águas turvas localizando peixes através de sistemas sonares altamente desenvolvidos, o boto enquanto guia nos trabalhos de pajés, pais e mães de santo nas religiões da Amazônia e o boto que se transforma em um homem branco e sedutor que se aproveita sexualmente das mulheres ribeirinhas, se apresenta enquanto meio analítico irredutível. De um ponto de vista estritamente ecológico, em sentido estrito, o que está em jogo neste caso é a conservação das diferentes espécies de boto em um ambiente que se transforma drasticamente pelas intervenções humanas. Aqui apresentamos brevemente o impacto da pesca sobre a vida aquática, mas a ecologia dos rios amazônicos inclui a atividade industrial, a mineração, as barragens, dentre outros fenômenos extrativistas que possuem um potencial destrutivo para os ecossistemas locais, sendo que animais que estão no topo da cadeia alimentar como os botos são especialmente afetados. A classificação recente do boto como uma espécie em perigo de extinção (o segundo maior grau de vulnerabilidade da Lista Vermelha da IUCN) é um índice de um processo com múltiplos desdobramentos. Um processo ecopolítico ligado ao avanço agronegócio, da monocultura e do capitalismo predatório dos grandes empreendimentos sobre a Amazônia, no qual tanto os ecossistemas quanto os sistemas socioculturais tradicionais são afetados.

O problema com o qual nos deparamos no âmbito da etnoecologia, neste contexto, diz respeito ao modo como o conhecimento tradicional tende, nesse campo, a ser dividido em dois: de um lado, o conhecimento empírico sobre o comporta- 
mento animal (que interessa); de outro, o conhecimento espiritual ou religioso (descartado com frequência nos termos de "lendas" e "mitos", ou "crenças"). O risco, nesse sentido, seria operar uma redução naturalista, convertendo a questão ambiental em uma realidade de fundo que determina o conjunto de transformações que analisamos.

O mesmo vale para as narrativas sobre o boto que assume a forma humana; neste caso a redução a ser evitada é aquela que delimita as relações em curso a partir das relações de poder e na dimensão prática das relações socioculturais. Em uma perspectiva estritamente sociológica, como vimos, a dimensão ecológica (os animais que nadam no rio) e a dimensão "cultural" ou "religiosa" muitas vezes interessam apenas em termos dos efeitos que provocam na sociedade, como no caso do boto quando atua como um álibi para a violência sexual que permeia as relações de gênero na Amazônia.

No mesmo sentido, uma perspectiva estritamente cosmológica tenderia a se concentrar nas relações entre narrativas. Quando se fala no boto como entidade que se manifesta no contexto espiritual ou religioso, os animais que vivem nos rios e as relações de poder tendem muitas vezes a serem lidas apenas como efeitos dos significados atribuídos a elas. A redução a ser evitada, neste caso, seria a redução ao campo do simbólico, entendido como a dimensão que fundamenta o conjunto de transformações em questão.

Em busca de uma chave de leitura capaz de operar a tripla irredução proposta, entendemos que o boto como uma entidade científica e o boto encantado são contínuos um com o outro, não podendo ser tratados como metáforas ou apenas como representações. É nesse sentido que recorremos a uma ampliação do campo semântico e conceitual da ecologia, tendo como referência o entrelaçamento ecosófico proposto por Guattari, das relações ambientais, sociais e espirituais. Este triplo entrelaçamento remete, por sua vez, ao que Isabelle Stengers chamou de uma ecologia das práticas ${ }^{20}$, que repercute e atualiza o conceito guattariano de ecosofia. Neste caso, nos interessa refletir a respeito do modo como as práticas religiosas ou espirituais e as práticas da biologia da conservação e da pesca se relacionam e se influenciam mutuamente a partir do caso dos botos.

O óikos (habitação, habitat, morada, o "eco" da ecologia) é concebido por Stengers como estando irremediavelmente conectado ao ethos (o modo de habitar, o comportamento). Isso significa que embora os comportamentos e ações dos diferentes organismos respondam ao ambiente como horizonte de possibilidades, eles também produzem ativamente o ambiente ao torná-lo habitável. Desta forma, o habitat de uma espécie é composto por - no sentido de que é determinado por e ao mesmo tempo age sobre - um conjunto de comportamentos e desdobramentos das vidas de outros seres. Os diversos modos como o boto interage com os peixes e com os pescadores, ou com os limites impostos pelas barragens, como reage e improvisa a partir desses outros actantes, perfazem os desdobramentos possíveis de um ambiente próprio, ou um mundo vivido. Trata-se, neste caso, do habitat enquanto perspectiva situada de um tipo de corpo, um conjunto de afetos e modos de perceber ${ }^{21}$.
20 Stengers (2005) formula este conceito ao investigar o campo de possibilidades que as práticas científicas constituem em suas interações com outras práticas.

21 Lembramos aqui do célebre conceito de Unwelt, formulado por von Uexküll (2010 [1934]). 
É nesse sentido da reciprocidade das interações que Stengers formula a ecologia das práticas. O habitat das práticas conservacionistas pode ser entendido, assim, como composto pela pescaria e permeado pela encantaria, em uma articulação que é recíproca. A pesca tradicional, por sua vez, poderia ser descrita como composta pela encantaria e permeada pela conservação do meio ambiente. A ecologia dessas práticas está ligada ao modo como elas se constituem mutuamente, mesmo que habitem mundos diferentes e possivelmente irredutíveis entre si. Um dos pontos daquilo que Stengers nomeia como cosmopolítica envolve uma compreensão da articulação entre as práticas que não implique na redução delas a um horizonte comum. Outro ponto é que as consequências dessas práticas (científicas, políticas, empresariais, ambientais) sejam discutidas diante daqueles que são afetados por elas, e que estes devam ser escutados (Stengers, 2005, 2018). Este último ponto nos parece crucial para refletirmos sobre ecologia política, particularmente no que se refere à relação entre a conservação da biodiversidade e os modos de vida tradicionais.

As histórias dos botos na Amazônia, nas quais se entrelaçam diferentes horizontes de práticas, envolvem processos de transformação que talvez só façam sentido a partir de uma concepção da humanidade e da animalidade que não seja baseada em essências fixas, mas antes em perspectivas cambiáveis. Botos estão ligados aos seres que possuem suas moradas no encante, em cidades semelhantes às nossas, localizadas no fundo dos rios. Ao visitar esse mundo em experiências oníricas ou ser levada pelos encantados, uma pessoa pode ficar lá para sempre. Em particular se comer ou beber o que lhe é oferecido por aqueles que encontra. Transformar-se em encantado, se encantar, é passar definitivamente para o lado de lá, para o desconhecido. Apenas os pajés são capazes de fazer essa jornada arriscada e retornar. Habitantes dos rios e de suas beiras, moradores das margens - laterais ou terceiras, submersas -, a convivência com seres como os botos envolve, neste contexto, uma vizinhança perigosa.

Ao pensarmos nessa vizinhança a partir das três ecologias, observamos que a degradação ambiental que leva os botos a estarem ameaçados de extinção se acha irremediavelmente ligada às mudanças nos tecidos socioculturais e subjetivo-espirituais amazônicos. Além das espécies ameaçadas, neste caso, uma série de práticas e modos de vida tradicionais - nos quais, como visto acima, o boto desperta temor engendra tabus e prescrições - encontram-se em perigo. A extinção das espécies de botos e a extinção dos modos de vida em que eles interagem com humanos são processos articulados entre si. É nesse sentido que, para além dos riscos implicados para as espécies "naturais", é preciso, igualmente, dimensionar o risco que correm essas "espécies existenciais", em que são também "movimentos” e "modos de sentir o mundo" que correm o risco de desaparecer (Lima, 2019, p. 387).

Espécies naturais e modos de vida, seres encantados e ecossistemas aquáticos, são ameaçados por um ideal de desenvolvimento que atualiza, hoje em dia, alguns dos aspectos mais nefastos do colonialismo. Diante deste quadro, tanto botos quanto pescadores tradicionais, assim como pesquisadores, precisamos mobilizar práticas capazes de resistir aos modelos predatórios que nos ameaçam coletivamente. 


\section{Referências}

ALMEIDA, Mauro W. Barbosa de. Caipora e outros conflitos ontológicos. R@U: Revista de Antropologia da UFSCar, v. 5, n. 1, p. 7-28, 2013.

BELAUNDE, Luisa Elvira. Resguardo e sexualidade (s): uma antropologia simétrica das sexualidades amazônicas em transformação. Cadernos de Campo, v. 24, n. 24, p. 538-564, 2016.

CALHEIROS, Orlando. As transformações do leviatã: praxiografia de um projeto de cetologia. 2009. Dissertação (Mestrado em Antropologia Social) - Universidade Federal do Rio de Janeiro, Rio de Janeiro, 2009.

CARNEIRO DA CUNHA, Manuela; ALMEIDA, Mauro W. B. Populações tradicionais e conservação ambiental. In: Cultura com aspas e outros ensaios. São Paulo: Cosac Naify, 2009.

DELEUZE, Gilles; GUATTARI, Félix. O que é a filosofia? Rio de Janeiro: Editora 34, 1992.

FIENUP-RIORDAN, Ann. The living tradition of Yup'ik masks: agayuliyararput - our way of making prayer. Seattle: University of Washington Press, 1996.

GALVÃO, Eduardo. Santos e visagens: um estudo da vida religiosa de Itá, Amazonas. São Paulo: Companhia Editora Nacional, 1955. (Coleção Brasiliana).

GOLDMAN, Irving. The mouth of heaven: an introduction to Kwakiutl religious thought. New York: John Wiley and Sons, 1975.

GUATTARI, Félix. As três ecologias. Campinas: Papirus, 1990.

HRBEK, Tomas; SILVA, Ver Maria Ferreira da; DUTRA, Nicole; GRAVENA, Waleska; MARTIN, Anthony R.; FARIAS, Izeni Pires. A new species of river dolphin from Brazil or: how little do we know our biodiversity. PLoS ONE, v. 9, n. 1, p. e83623, 2014. Disponível em: https://doi.org/10.1371/journal.pone.0083623. Acesso em: 18 dez. 2018.

LATOUR, Bruno. Irréductions. In: Les Microbes, Guerre et Paix, Suivi de Irréductions. Paris: Metaillé, 1984.

LATOUR, Bruno. Jamais fomos modernos: ensaio de Antropologia Simétrica. Crise; Relativismo. Rio de Janeiro: Editora 34, 2008 [1991].

LEACOCK, Seth; LEACOCK, Ruth. Spirits of the deep: a study of an Afro-Brazilian cult. New York: Anchor Press, 1972.

LESTEL, Dominique; BRUNOIS, Florence; GAUNET, Florence. Etho-ethnology and ethno-ethology. Social Science Information, n. 45, p. 155-177, 2006.

LÉVI-STRAUSS, Claude. O cru e o cozido. São Paulo: Cosac Naify, 2004 (1964). (Mitológicas 1$)$.

LIMA, Deborah de Magalhães. O homem branco e o boto: o encontro colonial em narrativas de encantamento e transformação (médio rio Solimões, Amazonas). Teoria e 
sociedade, p. 173-201, 2014.

LIMA, Vladimir Moreira. A partir de Guattari 1: uma política da existência. Rio de Janeiro: Ponteio-Dumará, 2019.

MAUÉS, Raymundo Heraldo. O simbolismo e o boto na Amazônia: religiosidade, religião, identidade. História oral, v. 9, n. 1, p. 11-28, 2006.

MONTGOMERY, Sy. Journey of the pink dolphins: an Amazon quest. Vermont: Chelsea Green Publishing, 2009.

PEACE, Adrian. Loving leviathan: The discourse of whale-watching in Australian ecotourism. In: KNIGHT, John (Org.). Animals in person: cultural perspectives on human-animal intimacies. New York: Berg, 2005.

SERVAIS, Véronique. Enchanting dolphins: an analysis of human-dolphin encounters. In: KNIGHT, John (Org.). Animals in person: cultural perspectives on human-animal intimacies. New York: Berg, 2005. p. 211-230.

SICILIANO, Salvatore; VIANA, Marcos César de Oliveira; EMIN-LIMA, Renata; BONVICINO, Cibele R. Dolphins, love and enchantment: tracing the use of cetacean products in Brazil. Frontiers in Marine Science, n. 5, p. 107, 2018.

SILVA, Vera M. F. da; FREITAS, Carlos E. C.; DIAS, Rodrigo L.; MARTIN, Anthony R. Both cetaceans in the Brazilian Amazon show sustained, profound population declines over two decades. PLOS ONE, v. 13, n. 5, p. e0191304, 2018. Disponível em: https://doi. org/10.1371/journal.pone.0191304. Acesso em: 18 dez. 2018.

SLATER, Candace. $A$ festa do boto: transformação e desencanto na imaginação amazônica. Rio de Janeiro: Funarte, 2001.

STENGERS, Isabelle. A invenção das ciências modernas. São Paulo: Editora 34, 2002 (1993).

STENGERS, Isabelle. A proposição cosmopolítica. Revista do Instituto de Estudos Brasileiros, Brasil, n. 69, p. 442-464, abr. 2018.

STENGERS, Isabelle. Introductory Notes on an Ecology of Practices. Cultural Studies Review, v. 11, n. 1, 2005.

UEXKÜLL, J. Von. A foray into the worlds of animals and humans. Minneapolis: University of Minnesota Press, 2010 [1934].

VASCONCELOS, Kauã. Nas margens de lá: entre caboclos e caruanas na encantaria marajoara. Rio de Janeiro: Editora da UFRJ/MN, 2020.

VAZ FILHO, Florêncio Almeida; CARVALHO, Luciana Gonçalves de. Isso tudo é encantado. Santarém: UFOPA, 2013.

VIRTANEN, Pirjo Kristiina. I turn into a Pink Dolphin-Apurinã youth, Awiri, and encounters with the unseen. In: Lost histories of youth culture, 2014. p. 105-122.

VIVEIROS DE CASTRO, Eduardo. Metafísicas canibais: elementos para uma antropologia pós-estrutural. São Paulo: Cosac Naify, 2015. 